\title{
El arquitecto Melchor de Velasco y el claustro del monasterio de Obona
}

\author{
María Josefa Sanz Fuertes \\ María José Buría Fernández \\ Universidad de Oviedo
}

\begin{abstract}
RESUMEN. En el siglo XVII, el claustro del monasterio de Santa María de Obona (Asturias) fue reconstruido; tras una breve introducción, este artículo se centra en la publicación de las fuentes documentales que prueban la participación del arquitecto cántabro Melchor de Velasco en la obra..

Palabras clave: Santa María de Obona (Asturias), claustro, Melchor de Velasco.

ABSTRACT. In the seventeenth century, the cloister of Santa María de Obona (Asturias) was newly rebuilt; after a brief introduction, this article shows the role played in it by Melchor de Velasco, an architect from Cantabria

Key words: Santa María de Obona (Asturias), cloister, Melchor de Velasco.
\end{abstract}

Cuando en 1994 Germán Ramallo publicó su estudio sobre la obra asturiana del arquitecto cántabro Melchor de Velas$\mathrm{CO}^{1}$, al referirse a la última de las obras firmadas por el mismo, el claustro del monasterio benedictino de Santa María de Obona, sito en el concejo de Tineo $^{2}$, da como fecha

${ }^{1}$ G. RAmAllo AsEnSIO, "El arquitecto Melchor de Velasco antes de su llegada a Galicia", Tiempo y espacio en el Arte. Homenaje al profesor Antonio Bonet Correa, Madrid, 1994, pp. 501-523.

${ }^{2}$ Sobre la fundación de este monasterio y el estado de la cuestión sobre la misma cf. Ma J. SANZ FUENTES, “Documentación Medieval del monasterio de Santa María de Obona en el Archivo Histórico Diocesano de Oviedo", Asturiensia Medievalia, 8 (1995-1996) 291-293. Una amplia bibliografía sobre el mismo es la recogida por V. RODRÍGUEZ OTERO, J. CAMINO MAYOR y J.M. PURAS HIGUERAS, "Excavaciones en el monasterio de Santa María la Real de Obona. Tineo. Asturias", Boletín del contrato establecido entre el arquitecto y la comunidad monástica el 26 de junio de 1658 y como fedatario al notario Juan Abe$1 a^{3}$. Pero el mismo autor, en nota a tal aseveración, afirma haber tomado la cita de la obra en que Pérez Constantí recogió todos los datos referentes a artistas que dejaron su huella en la Galicia de los siglos XVI y $\mathrm{XVII}{ }^{4}$ y reconoce textualmente que "buscando el citado escribano Juan Abella entre los de Oviedo, Gijón, Avilés, e incluso entre los de Tineo y Cangas de Tineo, no hemos

del Real Instituto de Estudios Asturianos, XLV, no 138 (1991) pp. 538-539, especialmente notas 6 y 7.

${ }^{3}$ Ibíd. p. 511.

${ }^{4}$ Cf. P. PÉReZ CONSTANTí, Diccionario de los artistas que florecieron en Galicia durante los siglos XVI y XVII, Santiago de Compostela, 1930. 
encontrado tal nombre, ni siquiera considerando el Abella como segundo apellido"s.

Debido al trabajo que por parte de una de las autoras de este artículo se viene desarrollando, para el que ha sido necesario consultar la documentación de protocolos notariales de Tineo de los siglos XVI, XVII y $\mathrm{XVIII}^{6}$, se ha podido localizar tal escritura de contrato y corregir con ello dos errores cometidos por Pérez Constantí que pudieron inducir a error a Ramallo Asensio.

El primero, y más destacado, ha sido el error en la transcripción del apellido del notario: se trata no de Juan Abella, sino de Juan Avello, notario público en el concejo de Tineo en las fechas en que el documento se expide. El segundo un error de datación que adelanta en un mes el otorgamiento de la escritura: Pérez Constantí la data el 29 de junio de 1658, cuando en realidad tal hecho ocurre el 29 de julio del mismo año.

Como diplomatistas que somos, nuestra contribución en este caso se limita a ofrecer la edición del documento, o más bien de los tres documentos que se conservan en el protocolo notarial de Juan Avello referentes a este hecho. $\mathrm{Y}$ es que si bién el motivo de que se hallen protocolizados en el mismo se debe a que ante él se otorga el contrato de obra, previos al mismo, necesarios para él, y entregados al notario para que se adjuntasen a la escritura encontramos otros dos documentos originales. El primero de ellos es la solicitud elevada por el abad y el convento de Obona al padre general de la Congregación de Castilla de la orden benedictina para que autorice la obra, solicitud que incluye un somero aunque muy aclaratorio informe sobre la situa-

${ }^{5}$ Cf. RAMAllo AsENSIO, ob. cit., p. 518, nota 29.

${ }^{6}$ En estos momentos Ma José Buría realiza, bajo la dirección de $\mathrm{M}^{\mathrm{a}}$ Josefa Sanz su tesis doctoral Hospitales de Peregrinos en el concejo de Tineo durante la Edad Moderna. ción de los edificios que conformaban el espacio monástico, el porqué de la necesidad de las obras y cuál era en ese momento su situación. Y el segundo, escrito al dorso del folio en que se extendió el primero, la licencia concedida por fray Diego de Silva, en aquellos momentos general de la orden.

Las firmas autógrafas de los otorgantes de los documentos nos llevan a constatar que en el momento en que se escrituraron habitaban en Obona siete monjes, incluyendo en este cómputo el abad, de ahí que no nos parezca a nosotras este claustro "ruín" ni "pobre", como lo calificó Jovellanos, ni que parezca "más casona de hidalgo que fábrica de convento"7, sino adecuado al número de habitantes y a las dificultades orográficas a las que necesariamente había de ajustarse.

Pero del análisis de la arquitectura que en las condiciones del contrato se estipulan no hemos de ser nosotras quienes nos ocupemos. Nuestra tarea concluye, como anteriormente hemos dicho, con ofrecer a los historiadores del arte los documentos editados según las normas de la Comisión Internacional de Diplomática. A ellos les corresponde en este caso utilizarlos para la Historia.

\section{DOCUMENTOS}

1

1658 , julio, 29, antea

Fray Bernardo Díaz, abad de Obona, junto con su convento, suplican a fray Diego de Silva, general de la congregación de San Benito, licencia para proseguir la obra del claustro y de otras dependencias monásticas iniciada por sus predecesores.

\footnotetext{
${ }^{7}$ Citas tomadas de RAmallo Asensio, ob. cit., p. 511 .
} 
A. Archivo Histórico de Asturias, Protocolos de Tineo, caja 15.593, fol. 52r.

Reverendísimo padre nuestro:

el padre abbad y monges, todos conbentuales, deste real monasterio de Santa María de Obona, humildes hijos de vuestra reverendísima, decimos, que este dicho monasterio, así por la antigüedad de sus edificios como porque en los prinçipios de su fundaçión no se edificó con la perpetuidad y firmeza neçessaria para su duraçión i ni tanpoco tiene havitaçión neçessaria, conveniente no solo para los monges que en tienpos futuros en él puede haber, pero ni para los que oy residen, por cuya caussa los padres abbades anteçessores se determinaron a derribar parte de los claustros y algunas de las çeldas y ofiçinas, edificando de nuevo un paño de claustro, con tal dispossiçión que neçessitaron a los que de nuebo entrassen a ser abbades a que prosiguiessen la obra, así porque se acortó la havitaçión poca que antes havía como porque lo restante del edifiçio quedó muy maltratado y con peligro de ruina por los reçios ayres y muchas nieves que le combaten.

Por tanto, a vuestra reverendísima humildemente supplicamos nos dé su lizencia para proseguir dicha obra en conformidad de una planta que oy está hecha, de que hazemos presentaçión a vuestra revereverendísima, ofreçiendo como offrezemos dar principio a ella por el quarto más neçessario y costosso, para que, vençida esta dificultad, que es la maior, queden en obligaçión y empeño los padres abbades suçessores a continuar la obra asta la última mano y el monasterio quede perfecto y en forma monachal y firme, con toda la havitaçión de zeldas y ofiçinas forçossamente neçessarias, que en esto nos hará vuestra paternidad reverendísima singular favor, etc.
Fray Bernardo Díaz, abbad de Obona (R). Fray Plácido de Villa (R). Fray Pedro de Llano (R). Fray Sebastián Ortiz (R). Fray Pedro de Vergara (R). Fray Joan Alvarez (R). Fray Iñigo Fernández (R). Fray Francisco Lasso (R).

2

1658, julio, 29. San Juan de Corias

Fray Diego de Silva, general de la Congregación de San Benito en España e Inglaterra, otorga su autorización para que en el monasterio de Obona puedan realizarse las obras que solicita su abad fray Bernardo Díaz.

A. Archivo Histórico de Asturias, Protocolos de Tineo, caja 15.593, fol. $52 \mathrm{v}$.

Vista la petición retroescrita por nuestro reverendísimo padre el maestro fray Diego de Silva, general de la Congregación de San Benito de España e Ynglaterra, etc., dijo su reverendísima que daba liçençia al padre abbad y demás monges del monasterio de Nuestra Señora de Obona para que puedan hacer la obra contenida en la sobredicha petiçión, otorgando la escritura o escrituras que parecieren necessarias para el ajustamiento y conclusión de dicha obra, por ser de la utilidad que en la dicha petición se refiere. $\mathrm{Y}$ por tanto mandaba al padre abbad del dicho monasterio de Nuestra Señora de Obona que prosiga dicha obra conforme a la planta que tiene hecha y presenta en esta petición ante su reverendísima, obligándosse en nombre de el dicho monasterio a pagar en su tienpo y en el de sus subcesores la cantidad de maravedís que se tratare en pago de dicha obra y a los plaços que le pareciere más combenientes, según y en la forma que en la sobredicha petición se pide, que para todo daba su reverendísima su facultad y decreto y lo 
mandaba por la grande utilidad que se le sigue al dicho monasterio.

Ansí lo probeyó y mandó su reverendísima en San Joan de Corias, a veinte y nuebe de julio de mill y seiscientos y cinquenta y ocho años.

\section{El General de San Benito (R).}

Por mandado de su paternidad reverendísima, fray Benito de Salazar (R).

$$
3
$$

1658, julio, 29. Santa María de Obona

Fray Bernardo Díaz, abad de Obona, en nombre de todo el convento, contrata con Melchor de Velasco, maestro de cantería, natural de la Junta de Ribamontán, merindad de Trasmie$r a, y$ residente en Oviedo, la construcción del nuevo claustro del monasterio y de otras dependencias, tal y como aparece estipulado en la escritura de contrato.

A.- Archivo Histórico de Asturias, Protocolos de Tineo, caja. 15.593, fols. 53r $56 r$.

En el real monasterio de Santa María de Obona, que es de la orden de San Benito, a veinte e nuebe días del mes de jullio de mil y seiscientos y çinquenta y ocho años, ante mí el escrivano público y testigos, pareçieron presentes de una parte su paternidad el mui reverendo padre fray Bernardo Díaz, abbad del dicho monasterio y señor de su coto, y los padres predicadores fray Pedro de Vergara, prior mayor, fray Plácido de Villa, fray Juan Alvarez, fray Pedro de Riaño, fray Iñigo Fernández, fray Sebastián Ortiz y fray Francisco Lasso, mayordomo, que son abbad, prior, monges y convento de dicho monasterio, estando juntos en su capítulo llamados por campana tañida, como lo tienen de costumbre, para tratar las cosas tocantes al servicio de Dios Nuestro
Señor y al vien y utilidad de su monasterio, de un acuerdo, nemine discrepante, y de la otra Melchor de Velasco, maestro de cantería residente en la çiudad de Oviedo, Prinçipado de Asturias, y natural de la junta de Ribamontán, merindad de Trasmiera, con liçençia, consejo y mandato del reverendísimo padre maestro fray Diego de Silba, general de toda la Congregación de San Benito en España, que, haviendo visto su paternidad reverendísima la planta de la obra que se ha de haçer en dicho monasterio y movido de la neçesidad que en él ay de çeldas y ofiçinas para la havitaçión de los monges y religiosos que al presente residen y por tiempo residieren y el peligro que tienen los edifiçios antiguos de dicho monasterio por caua de su mala fábrica y de que, haviéndose derrivado un paño del claustro, an quedado mui maltratados $\mathrm{y}$ desunidos unos de otros y mui deshiguales, con riesgo de caerse i dar a pique por los muchos aires que los convaten y nieves y tormentas que en esta tierra caen y se ven en tiempo de $h i<n>$ vierno, dio su decreto judiçial auténtico, firmado de su mano y refrendado de el secretario de la Congregación a las espaldas de una petiçión que presentó dicho padre abbad y monges de dicho monasterio, su fecha en San Juan de Corias, dicho día, mes y año; el qual decreto y petición se me exibió originalmente y va cosido con esta escritura, por el qual no solo consta dar su reverendísima liçençia para proseguir la obra començada, sino que expresamente manda que se conçierte toda la obra que resta haçer $/ 53 \mathrm{v}$ en dicho monasterio asta estar perfectamente acavado y con las çeldas y ofiçinas neçesarias en conformidad de lo deliniado en la planta.

Y usando el dicho padre abbad y convento de la dicha liçençia dada por su reverendísima, en que no solo permite se haga el conçierto de obrar lo que se pudiere en su quadrienio, sino que manda se haga el concierto de la obra dibuxada en la planta que vió su reverendísima, obligándose 
dicho padre abbad y su convento, por sí y por sus suçesores a pagar en los plaços determinados la cantidad de maravedises en que se conviniere con el dicho Melchor de Velasco, pagando en quadrienios cada uno de los padres abbades lo que tocare asta estinguir el dévito y concierto que se hiciere, y haviendo dado a su reverendísima notiçia de el conçierto que el padre abbad y santo convento hiçieron con el dicho Melchor de Velasco y las condiciones con que se avía de otorgar esta escritura, lo aprovó todo.

Y assí, el dicho padre abbad y santo convento digeron se obligavan y obligaron, por sí y en nombre de sus suçesores, por quienes prestaron capçión de rato, de dar y pagar al dicho Melchor de Velasco, maestro de cantería, por toda la dicha obra, en conformidad de las plantas que de ella se an hecho, onçe mill y cien ducados de vellón pagados en quinçe años, que se an de començar a contar de éste presente de mill y seisçientos y çinquenta y ocho asta la real paga de los dichos onçe mil y çien ducados; de los quales el dicho padre abbad presente, en los tres años que le restan de su abbadía, a de pagar forçosamente la quarta parte, que son dos mil seteçientos y setenta y çinco ducados; y si las rentas de el dicho monasterio alcançaren para poderle pagar, se ofreçió a haçerlo por las conveniençias que se le siguen de adelgaçar este dévito; y por las otras tres partes restantes digeron se obligavan en nombre de el dicho monasterio le serían çiertas y seguras en los doçe años siguientes, pagando cada uno de los primeros padres abbades suçesores dos mil seteçientos y setenta y çinco ducados; esto se entienda en caso que alguno de ellos no aia pagado más cantidad de la que se parte, porque en esse casso el dicho padre abbad último solo deverá pagar asta el cumplimiento de los sobredichos onçe mil y çien ducados de vellón; con condiçión que dicho Melchor de Velasco aia cumplido con las condiçiones siguientes:/ 54r 1.- Primeramente que en estos tres primeros años, conforme a las plantas, ha de dar perfectamente acavados dos quartos: el de la portería hasta la coçina y de allí el de refitorio hasta el aposento de moços ynclusibe, con todas sus celdas y oficinas y con los dos paños de claustro altos y bajos que le corresponden; y las dos torrecillas que $\mathrm{no}^{8}$ están en las plantas dibuxadas se an de fabricar sobre la mayordomía la una y sobre la barbería la otra, y cada una a de tener dos baras y media de alto, de texa vana, y cada una con dos bentanas.

2.- Yten que todas las paredes, puertas y bentanas se planten y eligan ${ }^{9}$ en los puestos que señalan las plantas. $\mathrm{Y}$ para aberle de dar prinçipio, se ronperán los cimientos de las paredes, dándoles quatro piés y medio de ancho, y ondarlos hasta hallar tierra firme o peña; y se eligirán dichas paredes con los dichos quatro piés y medio de ancho, con que subirán dichas paredes hasta el pavimento de la tierra.

3.- Yten que estando en el estado dicho arriva se escogerán las paredes con tres piés de grueso y subirán hasta el peso ${ }^{10} \mathrm{y}$ andar del corredor nuebo, de manera que todos los quartos se hallen al mesmo nibel y corriente en donde se echarán las soleras y bigas necesarias, repartiéndolas de modo que aya entre una y otra ocho pies de buelo.

4.- Yten es condición que, después de echadas dichas bigas y soleras, se elixa el último cuerpo de las paredes en dos piés y medio de grueso, con que se rematarán dichas paredes con el alto del corredor y desbán nuebo, en donde se echarán sus soleras para tillar los desbanes y tomar las aguas.

\footnotetext{
-

${ }^{8}$ Repite que no.

${ }^{9}$ Sic por erigir. Esta variante se repite con frecuencia; valga esta nota por todas las veces en que ocurre.

10 Sic por piso.
} 
5.- Yten es condición que los tres lienços del claustro que faltan se executen en la conformidad del que está fabricado nuebo hasta el primer suelo.

6.- Yten es condición que la bentana que está echa sobre el lienço del claustro se a de deshacer y bolber a darla otra nueba disposición, en conformidad de lo alzado, haciendo sobre cada uno de los beynte arcos de los quatro lienzos beynte bentanas con los mismos anchos y altos que señala el alzado; y se echará su cornixa por remate sobre los quatro paños del dicho claustro. $Y$ en dichos veynte arcos se pondrán sus petriles con el ancho de las pilastras en la forma que pareçiere al maestro.

7.- Yten es condición que todas las $154 \mathrm{v}$ puertas y bentanas que señalan las dos plantas altas y baxas será el cortezo de fuera labrado con su refaxo, y los esconces de mampostería con sus escazanes en la misma manera, cerradas de pazola. Pero las dos puertas, la que está para entrar en el claustro y la de la portería y las dos que se hacen para tomar la escalera y desenbarcar al corredor y las beynte bentanas que se hacen sobre los quatro claustros serán de sillería por todas haçes y con los labores que señalan las plantas. Toda dicha obra será bien labrada y las paredes bien maçiçadas y ligazonadas con todo cuidado y con buena mezca de cal, echándole dos carros de arena y uno de cal.

8.- Yten es condición que las tres puertas de las tres ospederías y la del granero se eligirán una bara más altas que las demás, por causa de la umedad; y para subir a ellas se an de hacer escaleras de piedra yngertas en la pared. Y que las briñas que están en la panera viexa se an de pasar a la nueba, reforzándolas en lo que fuere neçesario.

9.- Yten es condición que todo el material de cantería, carpintería, cerragería y clabazón aya de ser por quenta del maestro y todos los demás materiales neçesarios para dicha carpintería y cantería, cal arena y carretage.

10.- Yten es condición que dicho padre abad a de dar libres todos los montes, así de castaño como de roble, donde quiera que el convento los tenga y pueda cortar en ellos, de manera que al maestro no le cueste más que el beneficiarlo por su mano y portearlo como los demás materiales.

11.- Yten es condición que toda la carpintería a de ser por quenta del maestro y lo hará con su tabla y barrote bien echo y ajustado, y toda la madera que oy tiene el edificio viexo, así pontones como tablas y bigas, exceto en los corredores, que será toda la madera nueba para que haga labor con lo que está echo nuebo. Y la puerta de la portería y la que se sigue para entrar en el claustro y las tres de las ospederías y las otras que están para tomar la escalera y desenbarcar y la de la panería y refitorio y las $/ 55 \mathrm{r}$ de la cámara y las veynte que están sobre los paños de los claustros serán alinazadas, y todas las demás puertas y bentanas sobrepuestas.

12.- Yten que a de aber una caballeriza en la parte que pareciere a su paternidad y más cómoda parte.

Y es condición que dicho padre abad a de aderezar por su cuenta los caminos que están en los viages de las canteras y arenal, dando al maestro un ofiçial para asistir y travaxar con los peones.

13.- Yten es condición que todas las bigas, pontones y tabla que oy tiene la obra que se a de demoler, se a de labrar para bolberse a poner en la obra nueba, todo vien echo y ajustado.

14.- Yten es condición que, aunque al maestro se le dan los despojos de todo el edificio que a de caer, no se entienda que le ayan de pertenecer las rexas, canceles y alcobas, porque estas tocan y pertenecen al 
conbento. Y el maestro a de fijar por su cuenta dichas rejas y las demás que el convento $\mathrm{q}<\mathrm{u}>$ isiere en las bentanas que el convento señalare.

15.- Yten es condición que todos los tabiques que están señalados en las plantas por delgado y por dibisión de las celdas y sus apartamientos an de ser de marcos de madera y entre uno y otro marco se cerrará con su raxola, vien rebocado y blancado; y las dibisiones de dichas celdas no an de llebar puerta de madera, sino las de la celda de la cámara. Y en toda dicha carpintería se echará todo lo necesario, así de bigas como de soleras y sobremuros y todas las demás que conbengan para seguridad de la obra y para el tomar las aguas, cuyas corrientes an de ser grandes.

16.- Y más es condición que los puestos de los caleros, así de cantera como de leña, se an de dar al maestro, haciendo dicho padre abad toda la deligencia que pudiere porque sean libres y sin costa. $\mathrm{Y}$ en caso que ayan de costar algún dinero, se aya de pagar por mitad entre el monasterio y el maestro.

17.- Más es condición que en toda la circunferencia de la obra por el techo salga una falda de texado hasta tres quartas de salida de la pared afuera, de la echura de la que está sobre el corredor de la solana.

18.- Más es condición que sobre las cornixas del claustro se echarán sus cabeçillas de madera, que salgan fasta una quarta afuera del buelo de la cornixa, con su solera sobre dicha cornixa, con sus chaflanes para fundar $[\ldots ..] ; / 55 \mathrm{v}$ y tanbién echarán entre una y otra su tabique y el demás adorno de tabla y barrote.

19.- Yten es condición que la escalera se a de hacer en su sitio, con la misma madera que oy tiene, añadiéndole los pasos y la demás madera que faltare.
20.- Yten es condición que las puertas y bentanas an de llebar todo género de cerragería, que es bisagras, cerraduras de loba, picaportes, y las bentanas pasadores y aldabillas.

21.- Yten es condición que el refitorio a de quedar adornado de mesa, asientos y repaldares y púlpito, y el suelo enladrillado, y el cielo en la forma que está.

22.- Yten es condición que la entrada del coro se a de hacer con su puerta y escalera junto a la pieza que a de ser archibo; y se a de enladrillar el desbán del archibo, que es la pieza que oy sirbe de capítulo, y hacer su puerta de madera quaxada de planchas, dándolas el convento, y asentando en ella dos cerraduras que dará el convento.

23.- Yten es condición que como en estos tres años primeros el dicho maestro a de dar echos y perfectamente acavados los dos quartos de que ba echa minción, en los otros quatro años ymediatos a de dar echo y perfeto acavado el tercero quarto, que yncluye la bodega, granería y capítulo, y el bentanage del claustro que está pegado a la yglesia, de modo que en espacio de dichos primeros siete años toda la dicha fábrica a de quedar perfetamente acavada, y antes si pudiere, aviendo de poner el dicho maestro por su quenta todos los materiales necesarios para la dicha obra, sin que el conbento aya de dar más de los que aquí ban espresados.

En cuya conformidad todas las dichas partes lo efetuaron y otorgaron en la forma y con las condiciones dichas, las quales y todo lo contenido en este contrato se obligan de cunplir, pagar y guardar bien y puntualmente, conforme a las plantas y sin dubda ni exçeçión [alguna]. Y a ello y a todo lo que dicho es se obligan /56r con sus personas e vienes avidos e por aver, conforme a las plantas y alçado del claustro, que firmaron dicho padre abad y dicho 
maestro y rubricado de mí, escrivano, y la licencia del reverendísimo que aquí queda cosida. Y lo uno y lo otro an de cumplir y guardar como dicho es; y a ello se obligan en forma su paternidad y convento de mancomún y cada uno por el todo, y dicho maestro con sus bienes presentes y futuros, y que todo lo aquí contenido y espresado lo cunplirá, pena de quinientos ducados aplicados para la sacristía y altares desta yglesia y monasterio; por las quales non cumpiendo pueda ser executado ynprevisiblemente. Y dieron poder cumplido a las justizias del Rey nuestro señor se lo hagan cumplir como sentencia pasada en cosa juzgada. $Y$ renunciaron todas leis, fueros $y$ derechos de su favor, y la general. Y firmaron su paternidad y convento y dicho maestro, a quien doy fee conozco, estando testigos Juan Díaz y Toribio de Noriega y Juan Gutiérrez, maestros de cantería y carpintería, residentes en el concejo de Cangas y Tineo y que al presente están en dicho coto para dicha obra.

Fray Bernardo Díaz, abbad de Obona (R). Fray Plácido de Villa (R). Fray Sebastián Ortiz (R). Fray Francisco Lasso (R). Fray Pedro de Vergara (R). Fray Joan Alvarez (R). Fray Pedro de Riaño (R).

Melchor de Belasco (R).

Scripto en sello primero.

Ante mí Joan Avello, scrivano (R). 